\title{
Perancangan Perhiasan Tembaga dengan Finishing Perpaduan Patina dan Cat Dekoratif Menggunakan Metode Riset Praktik Eksperimental
}

\author{
Elliati Djakaria \\ Program Studi Interior Desain, Fakultas Seni Rupa dan Desain \\ Universitas Kristen Maranatha \\ elliatids@gmail.com
}

Received: 13 August 2021; Revised: 02 October 2021; Accepted: 28 December 2021

DOI: http://dx.doi.org/10.37905/aksara.8.1.525-538.2022

\begin{abstract}
Abstrak
Penelitian ini menggunakan metode riset praktik eksperimental-deskriptif, difokuskan pada perpaduan finishing patina dan cat dekoratif. Patina adalah sebuah proses lapisan film berwarna tipis yang beragam bentuk di permukaan tembaga, kuningan, perunggu dan sejenis logam lainnya, yang terbentuk melalui proses oksidasi atau proses kimia lainnya. Terbentuknya proses patina memerlukan waktu yang sangat lama hingga mencapai puluhan tahun, maka rekayasa percepatan dan penampilan serupa dapat dilakukan melalui patina buatan. Efek karat yang cepat dapat dilakukan menggunakan bahan kimia amonia, cuka, baking soda, garam, tawas dan gula. Penerapan untuk studi kasus pada perhiasan tembaga dengan mengembangkan beragam tekstur yang dapat memaksimalkan hasil finishing patina. Tujuan dari riset ini adalah mengidentifikasi metode perpaduan finishing patina dan cat dekoratif serta peralatan yang diperlukan dalam proses pembentukan tekstur pada tembaga hingga menghasilkan finishing yang maksimal untuk menambah nilai jual; mengetahui tahapan pelaksanaan proses penciptaan perhiasan tembaga mulai dari persiapan, pemilihan bahan, pengerjaan hingga finishing. Metode riset praktik eksperimen deskriptif dipilih karena peneliti terlibat langsung dalam setiap proses pengerjaan untuk mengetahui tingkat kesulitan dan kendala yang ditemui langsung pada prosesnya. Hasil riset ini adalah perhiasan berupa kalung, anting, dan gelang dengan perpaduan finishing patina dan cat dekoratif. Manfaat dari riset ini dapat menambah variasi finishing pada produk seni kriya logam tembaga, seperti perhiasan, furniture, produk lampu, patung, dan lain sebagainya.
\end{abstract}

Kata Kunci : Finishing; jewelery; patinasi; tembaga; variasi

\section{PENDAHULUAN}

Perancangan perhiasan tembaga terus mengalami perkembangan mengikuti perubahan jaman dan juga permintaan konsumen yang semakin bervariasi dan kompleks dalam pengerjaannya.

Terdapat tiga komponen penting penciptaan pada sebuah karya seni dan desain, dalam hubungannya memproduksi dengan nilai yang baru dan menemukan makna, yaitu keberadaan seorang seniman, karya seni (art work), dan audience yang mengapresiasi karya tersebut. Sebuah karya seni terdiri dari materi, medium dan bentuk. Materi seperti tembaga, bambu, kayu, dan sebagainya. Sedangkan medium dapat berupa karya seni kriya, karya musik, performance art, dan sebagainya. 
Malin, Ure dan Gray menuliskan penelitian berbasis praktik (practice-based research) adalah penelitian yang paling tepat untuk para perancang, sebagai penelitian yang dimulai dari kerja praktek dan melakukan praktek. Pengetahuan baru yang diperoleh dari hasil penelitian dapat diterapkan langsung pada bidang yang digeluti oleh para perancang. Peneliti menggunakan kemampuan dan pengetahuan yang dimiliki pada subjek tersebut. Caranya dapat dengan; 1) Studi kasus, 2) Observasi partisipan, 3) Gagasan-gagasan pribadi, 40 wawancara, kuesioner, 5) Analisis multidimensi, 6) Teknik evaluative (Malin, ure dan Gary,199:1).

Nuning dalam CORAK penciptaan sebuah karya seni berkaitan dengan eksplorasi yang dikembangkan melalui eksperimen. Metode dalam ranah penciptaan karya seni sangat mungkin dikembangkan menggunakan metode praktik berbasis riset (practice based research/: Jurnal Seni Kriya, 2015).

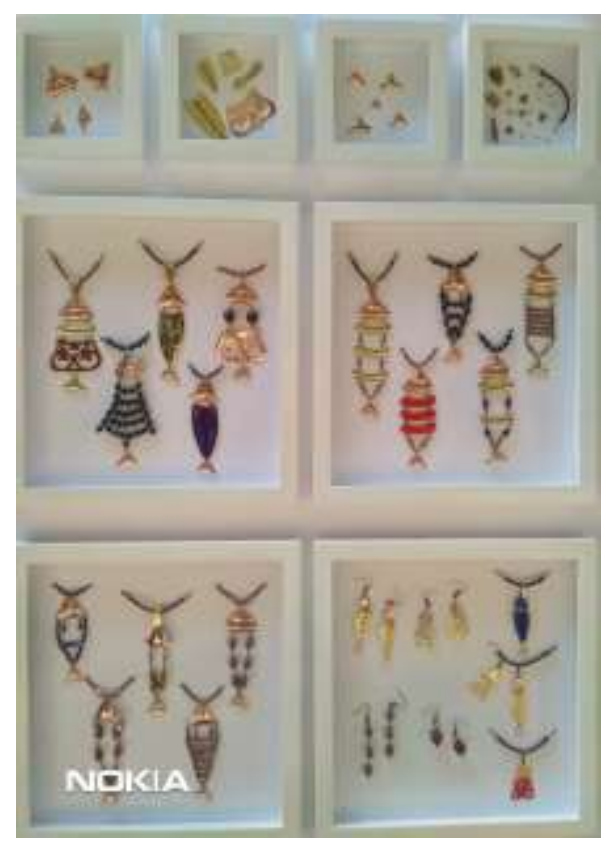

Gambar 1. Karya designer Jewellery Elliati Djakaria,

"Transformation Pattern", 2019

Melalui metode praktek berbasis riset, muncul ide untuk membuat inovasi baru dalam tampilan jewellery dari tembaga, peneliti melakukan penelitian perpaduan finishing efek patina dan cat dekoratif pada jewellery material tembaga.

Finishing akhir sebuah produk sangat menentukan penampilan akhir dari sebuah konsep desain yang sudah dirancang seorang desainer. Masyarakat Indonesia mayoritas menggunakan finishing electroplating, yakni melapisi cat clear coating seperti crystal coat atau pewarnaan menggunakan finishing opak pada perhiasan yang menggunakan material logam seperti tembaga dan kuningan.

Salah satu seniman yang menggunakan Teknik eksperimen adalah Febrian Wisnu Adi, beliau menyampaikan bahwa studi eksperimen finishing perhiasan kuningan dengan perpaduan electroplating dan patinasi, menggunakan eksperimennya dengan amonia, garam, baking soda, soda cuka, serbuk tawas belerang yang dipanaskan, yang 
disemprot amonia dan gula. Wisnu juga mengatakan dalam penelitiannya bahwa patina pada kuningan, material logam lebih mudah dalam pengerjaan dalam pewarnaan teknik patina (Febrian Wisnu Adi, CORAK : Wisnu: 2018).

Tulisan ini bertujuan menjelaskan proses penciptaan karya seni jewellery berbahan tembaga dengan finishing patina buatan dengan menggunakan bahan yang mudah didapat dan menggunakan alat-alat yang sederhana serta mendapatkan hasil yang maksimal. Tulisan ini juga bertujuan mengembangkan efek natural pada patinasi tembaga yang dapat meningkatkan nilai estetika dan dekoratif pada perhiasan tembaga yang mengalami proses patina buatan. Selain meningkatkan keawetan dan perlindungan pada kerajinan tangan logam, variasi finishing tembaga akan menambah variasi fashion jewellery sehingga menjadi lebih menarik, dan mampu meningkatkan minat masyarakat kepada kerajinan tangan Indonesia dan meningkatkan nilai komersial. Diharapkan hasilnya dapat menjadi salah satu solusi dalam menerjemahkan sebuah konsep desain ke dalam sebuah bentuk desain jewellery yang menggunakan tembaga sesuai dengan tampilan yang ingin disajikan.

Patina adalah lapisan film berwarna tipis yang beragam bentuk di permukaan tembaga, kuningan, perunggu, dan sejenis logam yang terbentuk melalui proses oksidasi atau proses kimia lainnya. Perubahan permukaan yang terjadi secara alami melalui proses pelapukan alami membutuhkan waktu bertahun tahun. Patinasi buatan adalah istilah membuat logam menjadi teroksidasi dan terbentuk korosi dengan terkena senyawa sulfur dan oksida, sehingga menimbulkan efek-efek warna yang bisa dikehendaki yang mengacu pada lapisan korosi yang berwarna biru -hijau, hijau, coklathitam, biru-hitam,kuning-coklat. Patina buatan dapat dilakukan menggunakan bahan sehari-hari seperti amonia, garam, baking soda, cuka, gula baik itu dengan pemanasan atau tidak dengan pemanasan.

\section{METODE}

Metode yang dilakukan dalam penciptaan karya seni ini adalah praktik berbasis riset yang dibagi dalam beberapa tahap, yaitu : Tahap I, studi literatur mengenai teknik finishing logam secara umum untuk rujukan eksperimen penerapan finishing ornamen pada logam dengan teknik patina; Tahap II, studi literatur mengenai patina pada tembaga untuk rekomendasi desain perhiasan logam; Tahap III, eksperimen penerapan finishing patina dan cat dekoratif pada logam dengan beragam tekstur ; Tahap IV, pembuatan bandul, gelang dan anting dari logam dengan perpaduan finishing patina dan cat dekoratif; Tahap V, analisis dan eksplanasi antara konsep pemikiran dalam penelitian berdasarkan tahapan-tahapan yang telah dilakukan sebelumnya. 


\section{Diagram Alur Penciptaan Perhiasan}

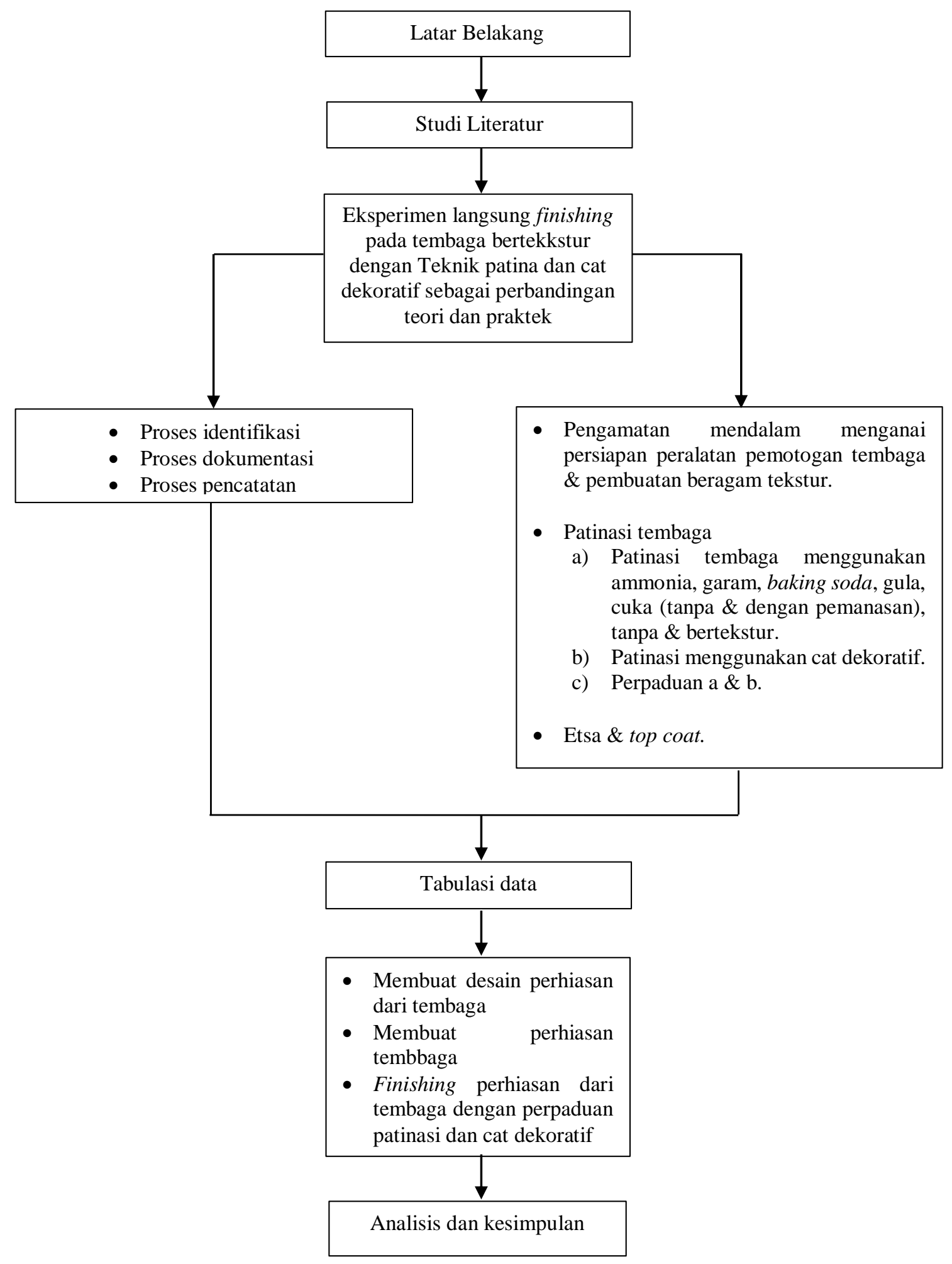

Diagram 1. Alur penciptaan perhiasan 


\section{PEMBAHASAN}

\section{A. Konsep Penciptaan}

Tembaga adalah salah satu material yang belum terlalu banyak dikembangkan, baik di jewellery, produk furniture, kerajinan tangan, dan pekerjaan Interior. hal tersebut disebabkan proses pengerjaannya belum terlalu popular dan perlu alat-alat khusus untuk membuat variasi tekstur yang menarik dan beragam.

Finishing yang baik dan menarik akan meningkatkan nilai keindahan (dekorasi), menambah perlindungan sehingga meningkatkan keawetan bahan dasar produk tersebut. Niali tambah ini menjadi daya tarik produk bagi pembeli untuk digunakan sehari-hari atau sebagai koleksi.

Tembaga adalah material yang memiliki korosi yang sangat cepat, mudah ditempa (liat) dan bersifat mulur sehingga mudah dibentuk menjadi perhiasan, pipa, lembaran tipis dan kawat. Sifat kimiawi tembaga tidak bereaksi dengan air, namun ia bereaksi perlahan dengan oksigen dari udara membentuk lapisan coklat-hitam tembaga oksida. Berbeda dengan oksidasi besi oleh udara, lapisan oksida ini kemudian menghentikan korosi berlanjut. Lapisan verdigris (tembaga karbonat) berwarna hijau dapat dilihat pada konstruksi-konstruksi dari tembaga yang berusia tua, seperti pada patung Liberty. Tembaga bereaksi dengan sulfida membentuk tembaga sulfide.

Eksperimen Langsung finishing pada tembaga dengan bermacam-macam tekstur dilakukan pada tembaga berukuran $3 \times 8 \mathrm{~cm}$. Dimulai dengan pemotongan plat tembaga berukuran 3 x $8 \mathrm{~cm}$, lalu dilakukan pembakaran kepada tiap lempengan tembaga tersebut. Setelah selesai selesai pembakaran, tembaga dimasukkan kedalam cairan air hangat yang ada di slow cooker yang sebelumnya sudah dinyalakan.

Proses ini dilakukan agar kerak kerak hasil pembakaran terlepas dengan sempurna. Setelah kurang lebih 2- 5 menit, atau sampai kerak terlepas, tembaga dapat dicuci dengan cara air bersih yang sudah ditempatkan kedalam ember, lalu dikeringkan menggunakan lap dari kain kaos. Dilanjutkan dengan membuat tekstur dengan menggunakan palu yang bermata yang bulat, palu yang bermata lurus, dan menggunakan mesin pengepresan menggunakan kain tile yang bertekstur halus. Hasilnya dapat dilihat pada foto dibawah.

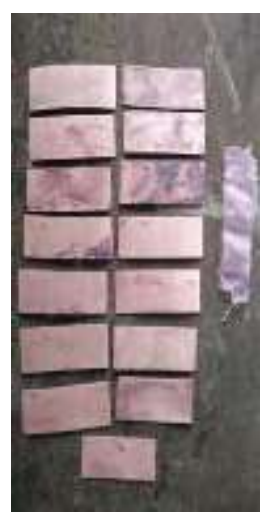

Gambar 2. Tembaga dengan tekstur halus

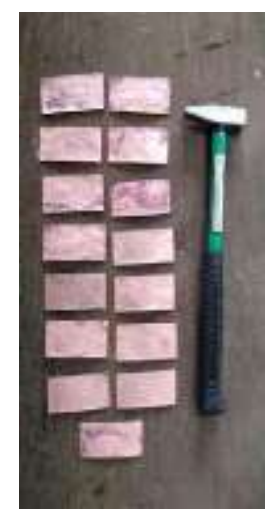

Gambar 3. Tembaga dengan tekstur garis

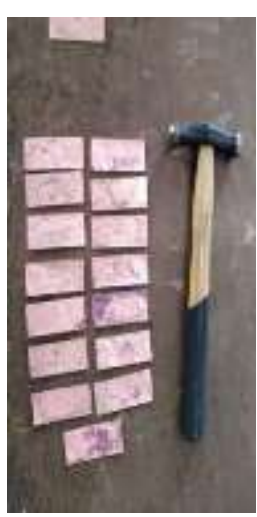

Gambar 4. Tembaga dengan tekstur bulat besar 
AKSARA: Jurnal Ilmu Pendidikan Nonformal

P-ISSN 2407-8018 E-ISSN 2721-7310 DOI prefix 10.37905

Volume 08, (1), January 2022

http://ejurnal.pps.ung.ac.id/index.php/Aksara

\section{B. Proses Patina pada Tembaga}

Proses Pengerjaan Patina dilakukan dengan mengguanakan masker dan sarung tangan.

1. Pengaplikasian proses patina dengan mengoleskan bahan ammonia, Garam, cuka, baking soda, tawas, gula diatas tembaga bertekstur kecil, sedang, dan besar dengan dan tanpa pemanasan. Dilakukan menggunakan koas

2. Pengaplikasian proses patina dengan mengoleskan bahan Amonia + garam; Amonia + Baking soda; Amonia+ cuka; Amonia + Tawas; Amonia+gula dengan diolekan dua kali.

\begin{tabular}{|c|c|c|c|c|c|}
\hline No & Zat & Deskripsi & $\begin{array}{c}\text { Finishing } \\
\text { Setelah peugalesan zat } 2 x\end{array}$ & $\begin{array}{c}\text { Finishing } \\
\text { Setelah dibersihkan }\end{array}$ & $\begin{array}{l}\text { Finishing } \\
\text { Etsa Towe \& Finhating } \\
\text { Contal Cout }\end{array}$ \\
\hline 1 & $\begin{array}{c}\text { Amania } \\
\text { Garam }\end{array}$ & 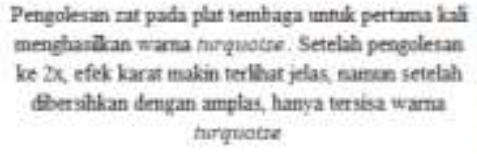 & & & \\
\hline 2 & $\begin{array}{l}\text { Amania * } \\
\text { Bsaling Soda }\end{array}$ & 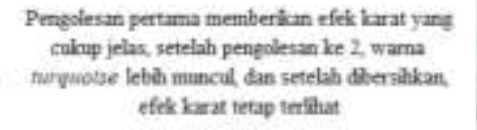 & & & \\
\hline 3 & $\begin{array}{c}\text { Amenia + } \\
\text { Cula }\end{array}$ & 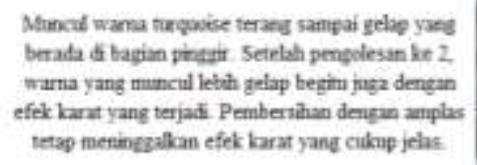 & & & \\
\hline 4 & $\begin{array}{l}\text { Amenia + } \\
\text { Tawas }\end{array}$ & 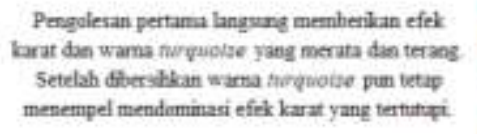 & & & \\
\hline 5 & $\begin{array}{c}\text { Amonia } \\
\text { Cela }\end{array}$ & 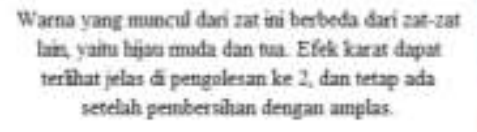 & & & \\
\hline
\end{tabular}

Tabel 1. Proses patina terhadap tembaga

3. Pengaplikasian proses patina dengan mengoleskan bahan Amonia + tawas + garam; Amonia + tawas + Baking soda; Amonia + tawas + cuka; Amonia + tawas + gula.

\begin{tabular}{|c|c|c|c|c|c|}
\hline Ne & Zat & Deskripei & $\begin{array}{c}\text { Finishing } \\
\text { pengelesas in 2x }\end{array}$ & $\begin{array}{c}\text { Finisbieg } \\
\text { Setelab tunggu } \\
2 \text { minesu \& dibersiakas }\end{array}$ & $\begin{array}{c}\text { Finishing } \\
\text { Etsa tene } \Delta \text { Crystal cont }\end{array}$ \\
\hline 6 & $\begin{array}{l}\text { Amonis }+ \\
\text { Tawas }+ \\
\text { Caram }\end{array}$ & 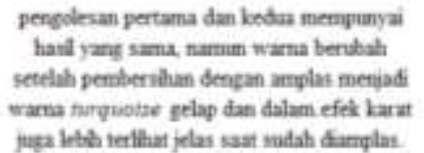 & & & \\
\hline
\end{tabular}


Amania - dari pengolesan pertama das kedas warna Tawas - yant muncul leth ceodenme tiru mada Bakine pacit namm bentab setrlah diberalkan Sodh denrm efeik karat yane grlap dan jelas.

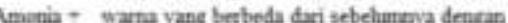 wama hurpuotse, hibe dan tiru. Efel barat dan sedlakr wama biru juea tetap ada setelal.

canpuran ketign rat in menebaskan warsa. diberithan.

Aminia - pada penedesan pertana efra karat sudul Tawas * trmbenuk desgan culcop but begitu juga Gula sampai proses pentersatan

Amonis - mancul wema bija dan birv tarpa warna

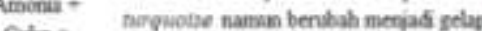
setelah proses penibenihan Efek brat serthat dengan jelas.
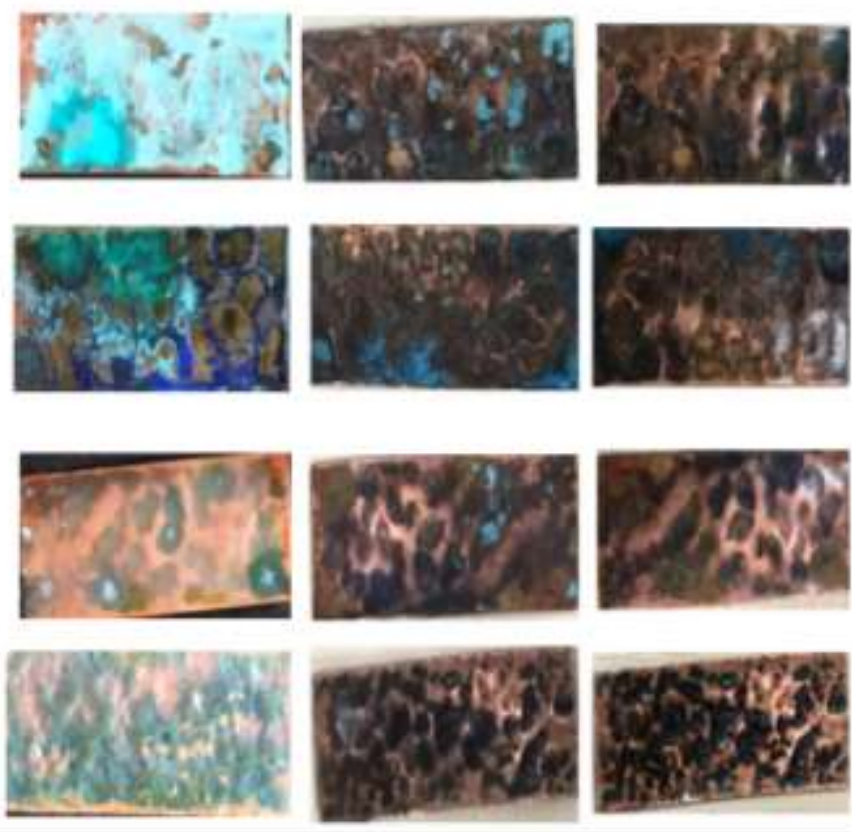

Tabel 2. Proses patina terhadap tembaga

4. Pengaplikasian proses patina dengan mengoleskan bahan Amonia + garam; Amonia +baking soda; Amonia + cuka; Amonia+ tawas; Amonia + gula dengan pemanasan.

\begin{tabular}{|c|c|c|c|c|c|c|}
\hline \multirow{2}{*}{ No } & \multirow{2}{*}{ Zat } & \multirow{2}{*}{ Proses } & \multirow{2}{*}{ Deskripsi } & \multicolumn{3}{|c|}{ FOTO MASIL. PATINASI } \\
\hline & & & & pengolesan zat $1 \mathrm{x}$ & Setelah dibersihkan & Finithing Crystal ceat \\
\hline 16 & $\begin{array}{l}\text { Amonia - } \\
\text { faww - } \\
\text { Oaram }\end{array}$ & $\begin{array}{l}\text { Pemanasan } \\
\text { Zat, } \\
\text { pengolesan ix }\end{array}$ & 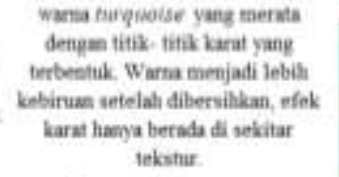 & & & \\
\hline 17 & $\begin{array}{l}\text { Ammia + } \\
\text { Tawas - } \\
\text { Aaking Soda }\end{array}$ & $\begin{array}{c}\text { Petranasan } \\
\text { Zat, } \\
\text { penpolesan is }\end{array}$ & 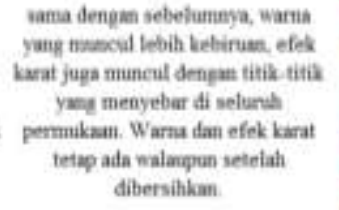 & & & \\
\hline 18 & $\begin{array}{c}\text { Amonia - } \\
\text { Tamat - Cuka }\end{array}$ & $\begin{array}{l}\text { Pemanasan } \\
\text { Zat, } \\
\text { pengolesan ix }\end{array}$ & 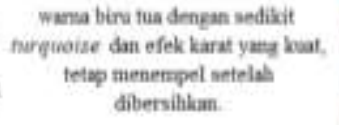 & & & \\
\hline 19 & $\begin{array}{c}\text { Amonia + } \\
\text { Tawas - Oula }\end{array}$ & $\begin{array}{c}\text { Pemianasan } \\
\text { Znt, } \\
\text { pengolesan is }\end{array}$ & 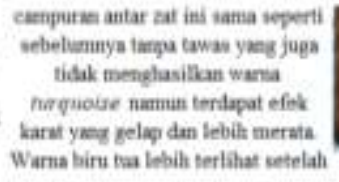 & & & \\
\hline 20 & $\begin{array}{l}\text { Amonia - } \\
\text { Cuka + Oula }\end{array}$ & $\begin{array}{l}\text { Pemanasan } \\
\text { Zat, } \\
\text { pengoirsan is }\end{array}$ & $\begin{array}{l}\text { warna pocat biru kehijauan tarpa } \\
\text { efek karm. Broses pembersilan } \\
\text { menghasiban warna birs tus dan } \\
\text { efek karst pofa tekstur. }\end{array}$ & & & \\
\hline
\end{tabular}

Tabel 3. Proses patina terhadap tembaga 
5. Pengaplikasian proses patina dengan mengoleskan bahan Amonia + tawas + garam; Amonia +tawas + baking soda; Amonia + tawas + cuka; Amnonia + tawas + gula; Amonia + cuka + gula.

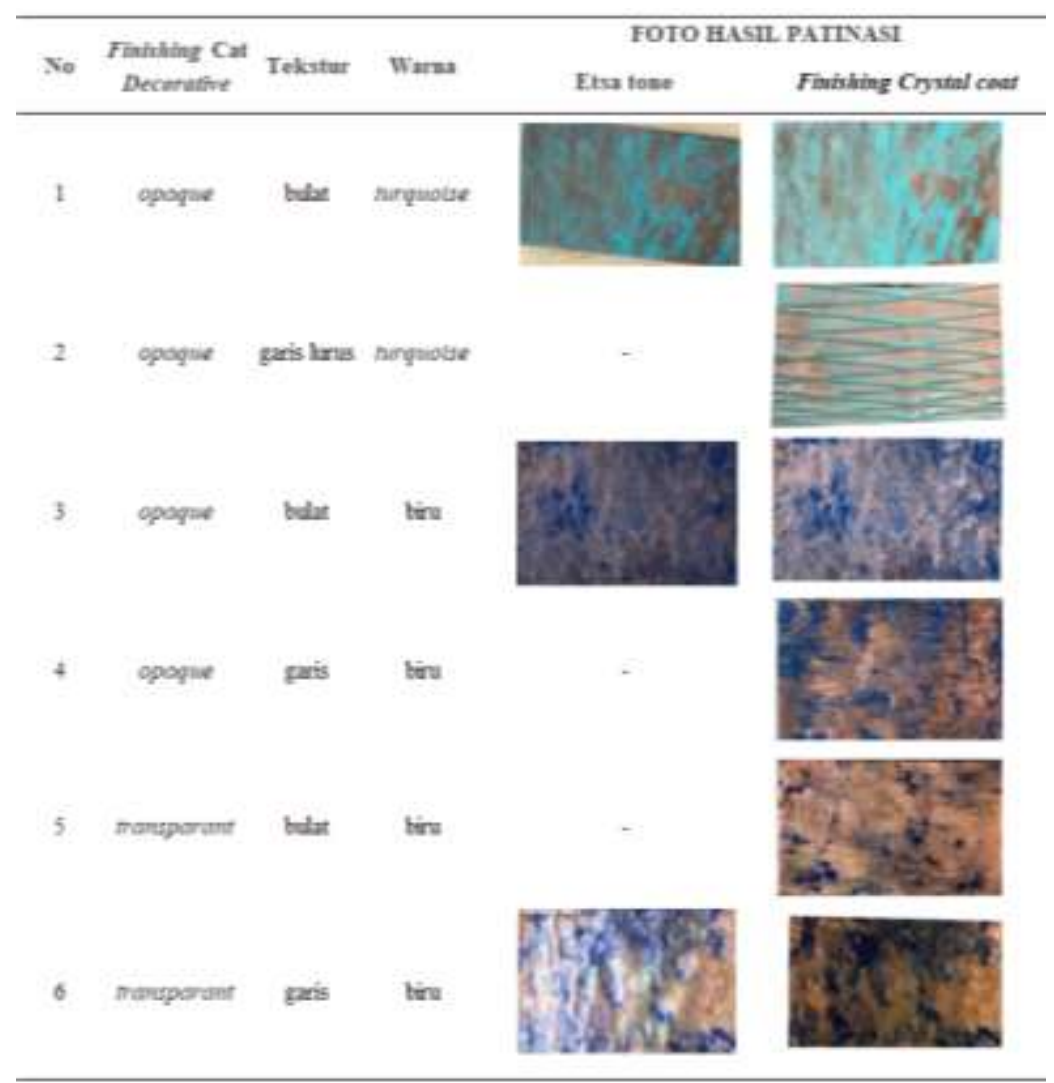

Tabel 4. Proses patina terhadap tembaga

Setelah selesai penghampelasan dengan hamplas nomer seribu ditambah air, dilakukan dengan cara berputar dan sangat hati-hati, agar patinasi yang sudah terjadi tidak terangkat semua. disini kita dapat melakukannya sesuai dengan hasil akhir pewarnaan yang diinginkan.

Setelah itu sebagian hasil akhir dilakukan coating dengan menambahkan efek etsa. Untuk membuat hasil patina tidak lepas, kembali dilakukan penyemprotan terakhir dengan top coat crystal coat dilakukan menggunakan alat semprot (spray gun). Setelah itu semua peralatan spray gun dapat dicuci menggunakan thinner laba-laba merah.

Proses Finishing menggunakan cat dekoratif yang opak warna biru dan turqouis dilakukan dengan mengoleskan cat diatas tembaga yang bertekstur kasar atau besar menggunakan koas. setelah itu dilakukan penghapusan cat menggunakan kain kaos yang sudah diberi thinner sehingga sebagian cat yang sudah dioleskan terhapus, sehingga cat yang berada dilekukan tekstur akan tertinggal.

Selanjutnya proses dilakukan menggunakan warna transparan biru dan ditambahkan efek etsa. Coating akhir dilakukan menggunakan crystal coat gloss. 


\section{Proses Penciptaan Jewellery}

Rancangan desain bandul, gelang dan anting, dimulai dengan proses sketsa, lalu diaplikasikan ke aplikasi corel draw untuk di laser cutting.

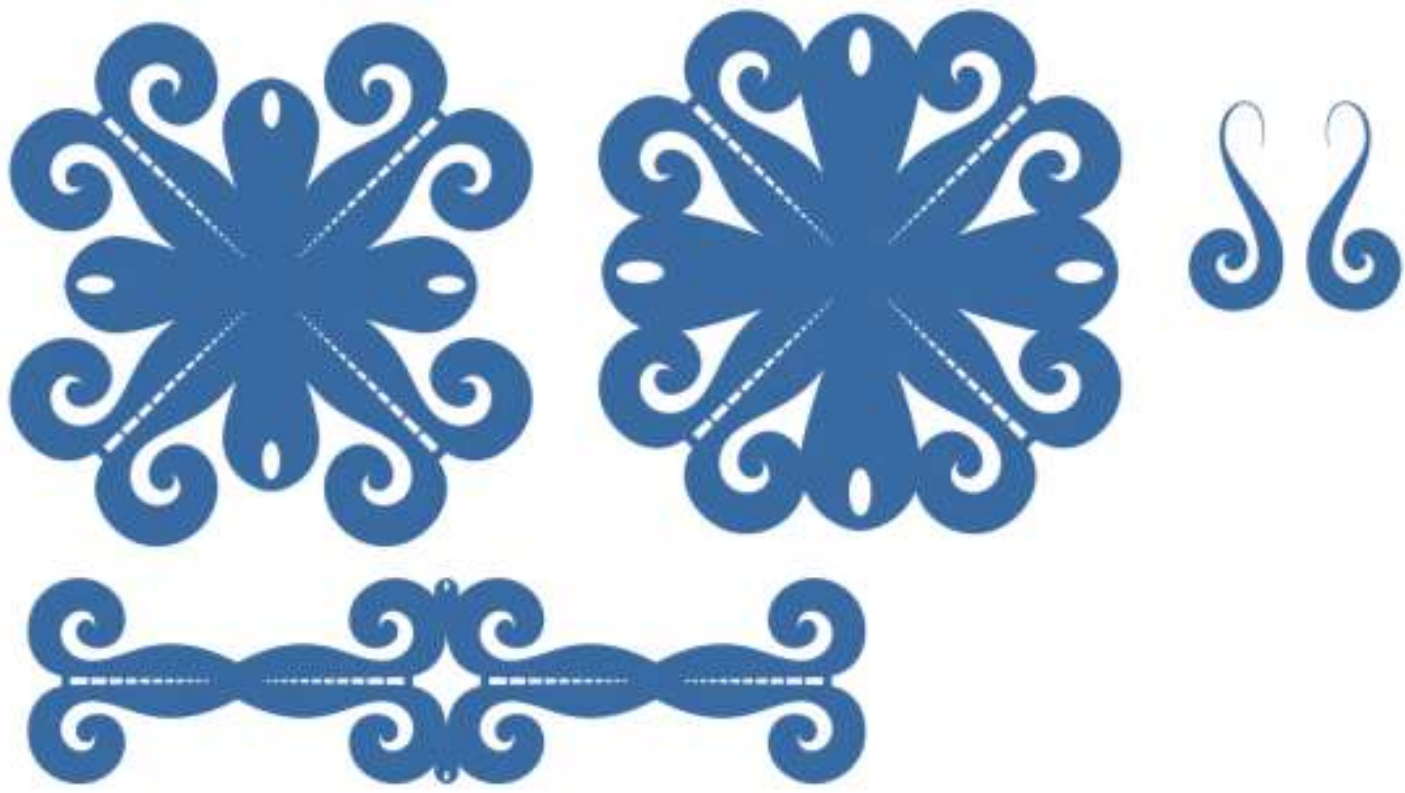

Gambar 5. Desain bandul, gelang, dan anting

Pemotongan tembaga dengan laser cutting menggunakan teknologi yang ada dan bertujuan untuk mempercepat proses pengerjaan.

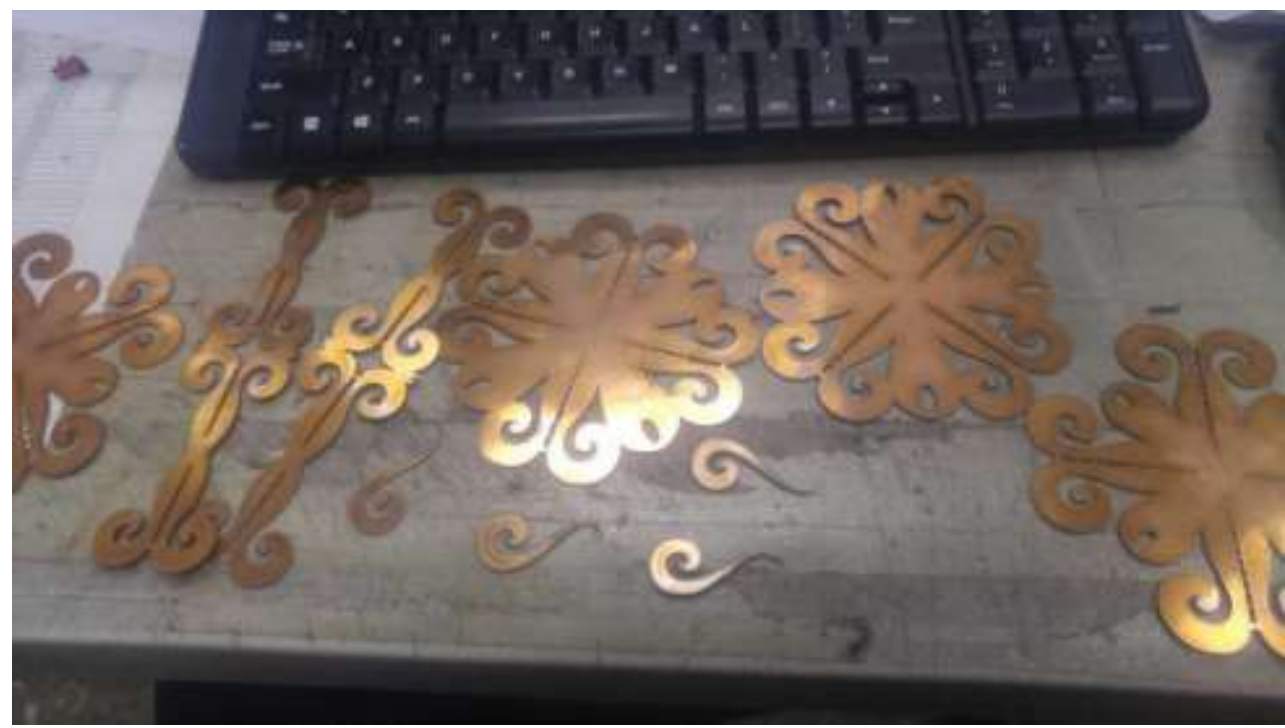

Gambar 6. Hasil pemotongan tembaga menggunakan laser cutting 
Setelah itu dilanjutkan dengan menghampelas dan menggunakan hampelas yang kasar (Norton nomor 240) untuk menghaluskan bekas proses laser cutting yang tajam, terutama bagian ujung-ujung yang tajam. Selanjutnya dilakukan penghalusan dengan hampelas nomor 240, nomor 600, dan nomer 1000. Setelah itu dapat dilanjutkan ke proses ke pembersihan tembaga yang akan langsung melalui tahap finishing, dapat dicuci dengan campuran vixal dan air dengan perbanding $5 \mathrm{ml}$ dan 1 liter air.

Langkah berikutnya dilakukan pembakaran tembaga persiapan untuk membuat tekstur. Pembakaran tembaga dilakukan di atas piring pembakaran dengan api sedang secara merata, agar pembakaran terjadi dengan sempurna

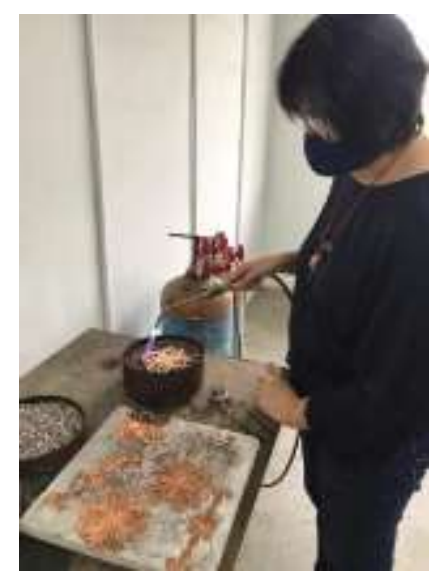

Gambar 7. Proses pembakaran

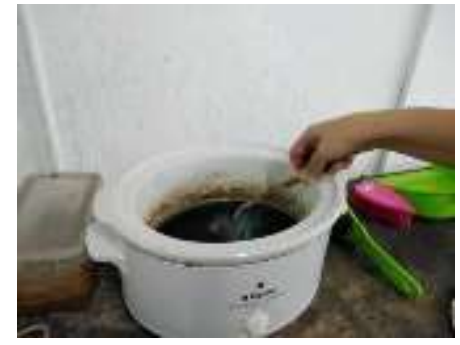

Gambar 8. Proses pembersihan

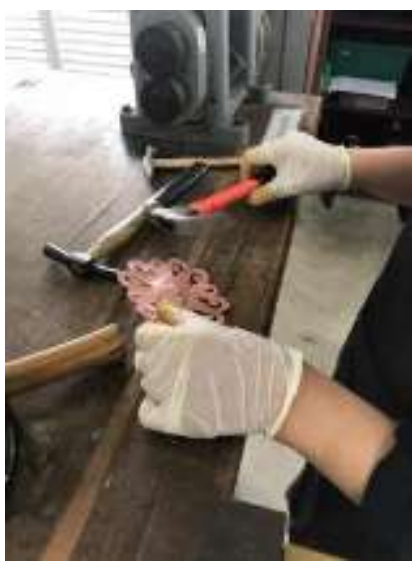

Gambar 9. Proses pembuatan tekstur

Setelah selesai pembakaran, tembaga dimasukkan ke dalam cairan air hangat yang ada di slow cooker yang sebelumnya sudah dinyalakan. Proses ini dilakukan agar kerakkerak hasil pembakaran terlepas dengan sempurna. Setelah kurang lebih 2- 5 menit, atau sampai kerak terlepas, tembaga dapat dicuci dengan air bersih yang sudah ditempatkan kedalam ember, lalu keringkan menggunakan lap dari kain berbahan kaos. Dilanjutkan dengan membuat tekstur dengan menggunakan palu yang bermata yang bulat. Setelah itu dilakukan penghampelasan dengan menggunakan hamplas nomer 1000 dibantu menggunakan sedikit air.
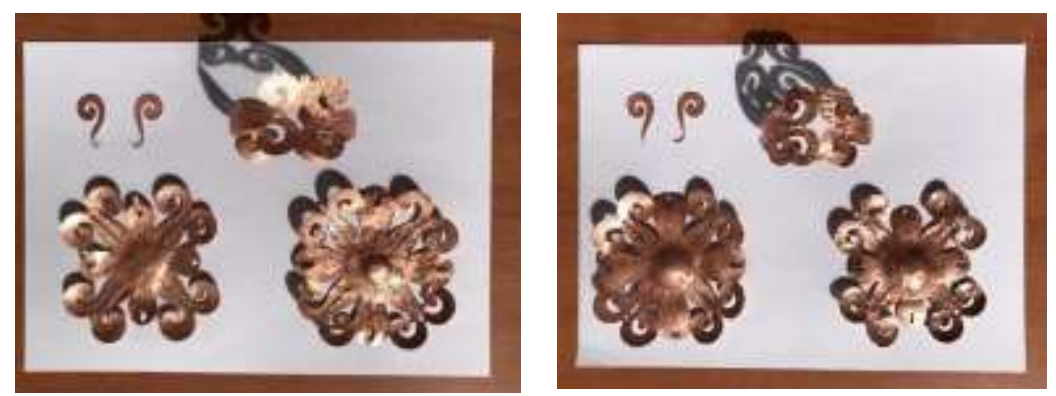

Gambar 10. Hasil Jewellery yang telah ditekstur 


\section{Proses Pengerjaan Patina}

Pengerjaan patina dilakukan pada 2 set perhiasan dengan pengolesan dengan ammonia yang dipanaskan sebanyak 2 kali untuk membentuk karat. Setelah itu perhiasan satu set dilakukan pengolesan dengan cuka dan gula sebanyak 2 kali. Warnanya berubah kebiru-biruan. Dan satu set lagi dilakukan pengolesan dengan tawas dicampur air yang dipanaskan dan hasil warnanya kearah turkis. Setelah ditunggu 1 minggu, lalu dilakukan pengampelasan dengan cara berputar dan sangat hati-hati, dengan hamplas nomor seribu, agar patina yang sudah terjadi tidak terangkat semua. Disini kita dapat melakukannya sesuai dengan hasil akhir pewarnaan yang diinginkan.

Hasil yang didapatkan proses warna patina kurang menonjolkan warna turkis, sehingga peneliti memodifikasi warna tukis dengan menggunakan cat dekoratif. Dilakukan sangat hati-hati sesuai dengan hasil akhir pewarnaan yang diinginkan.

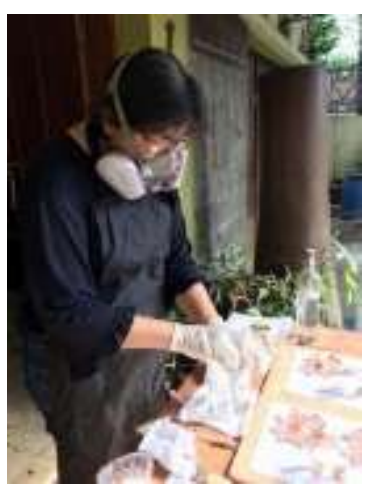

Gambar 11. Persiapan pengolesan dengan ammonia yang dipanaskan

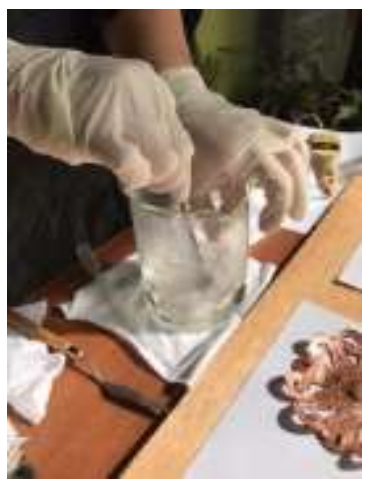

Gambar 12. Persiapan pengolesan cuka + gula + tawas yang dipanaskan

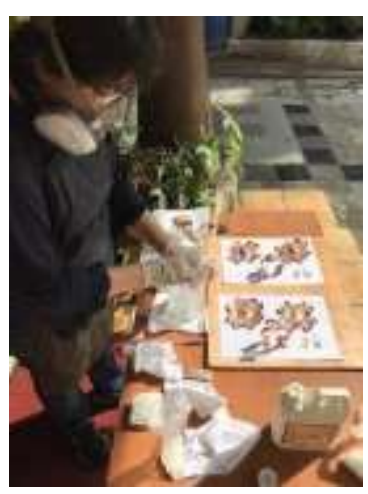

Gambar 13. Pengolesan dengan ammonia yang dipanaskan kedua kalinya

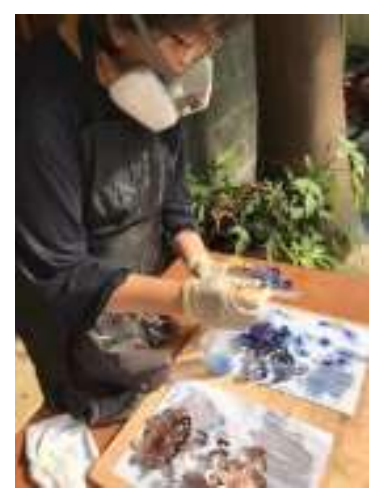

Gambar 14. Pengolesan cuka +gula+tawas yang kedua kalinya

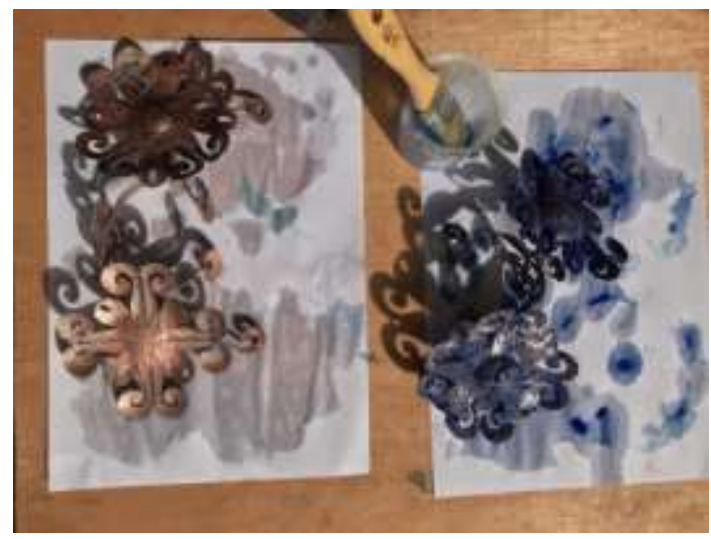

Gambar 15. Setelah 2 hari warna berubah dari warna biru menjadi warna turkis dan yang warna hijau menjadi kehijau-hijauan

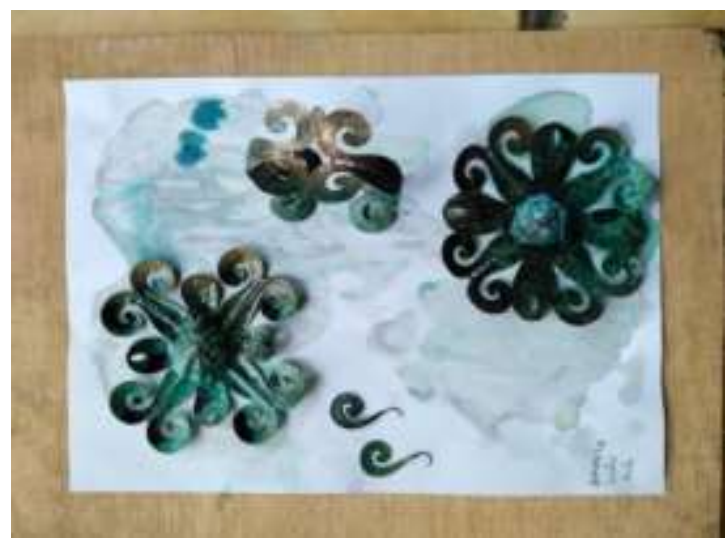

Gambar 16. Patinasi dengan ammonia + cuka + gula 


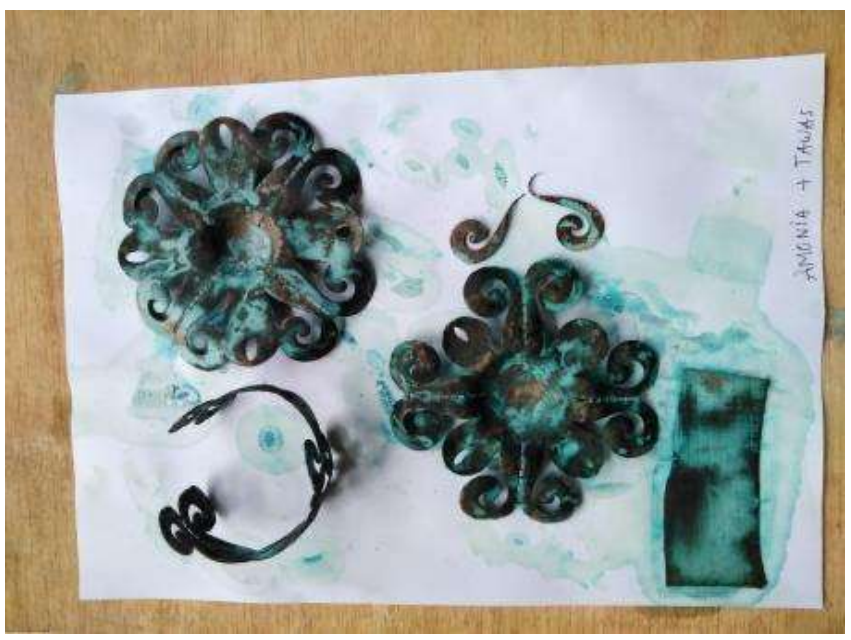

Gambar 17. Patinasi dengan ammonia + tawas

Untuk menonjolkan karakter natural, maka peneliti melakukan penyemprotan dengan lapisan cat etsa tone yang dicampur cat top coat yang tranparan. Setelah kering dilakukan sekali lagi untuk memastikan bahwa warna tidak berubah dan cepat memudar.

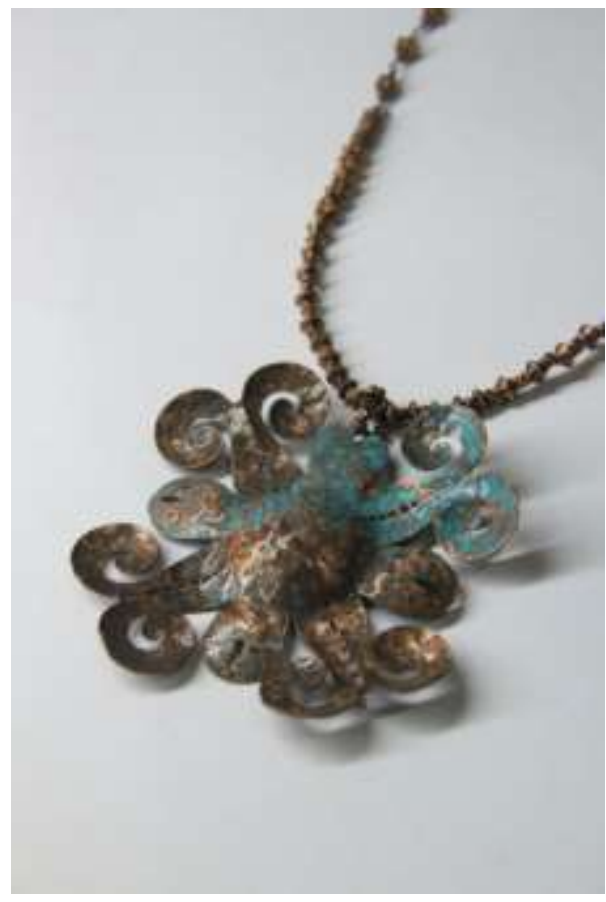

Gambar 18. Karya kalung dengan perpaduan patina dan cat dekoratif

\section{KESIMPULAN}

Proses penciptaan Karya Seni berkaitan dengan eksplorasi dimana dapat dikembangkan banyak eksperimen didalamnya. Variasi baru perpaduan patina dan cat dekoratif dapat menambahkan variasi finishing tembaga yang menarik pada karya seni dan produk jewellery, home décor, dan produk lainnya. 
Penelitian dengan metode penggabungan teknik patinasi dan cat dekoratif yang transparan dan opak, serta untuk menambah efek natural dilakukan pelapisan cat etsa tone yang dicampur cat top coat yang tranparan merupakan finishing sebagai sentuhan akhir terhadap suatu produk dengan tujuan meningkatkan nilai mutu bahan, meningkatkan nilai dekoratif, meningkatkan nilai estetika pada suatu produk, dan meningkatkan nilai jual suatu produk.

Bahan patinasi amonia, garam, baking soda, cuka, serbuk tawas, gula dapat menghasilkan patinasi yang sangat menarik, dan mudah dalam pengerjaannya serta menggunakan alat-alat yang sederhana. Tahapan pengerjaan yang tepat akan menghasilkan patinasi dengan warna yang diinginkan. Seperti mengoleskan perpaduan bahan yang dipanaskan dan sedikitnya dua kali pengolesan. Proses dilakukan dengan pemanasan membantu proses karat lebih cepat.

\section{REFERENSI}

Febrian Wisnu (2018) Studi Eksperimen Finishing Perhiasan Kuningan dengan Perpaduan Elektroplating dan Patinasi , jurnal Seni Kriya vol 7 no 1

Gray,Carol.Malins,Julian.2004. Visualizing Research, A guide to the research process in art and design. Ashgate Publishing Limited. 1998. "Inhuire through practice: Developing approprieate research strategies in art and design". University of Art \& Design Helsinki.

Karen Dougherty (2011) Metal Style, Loveland, Interweave Press LLC Albert Jacksond, and David Day (1997), Good Wood Finishes, London, HarperCollins Publishers Fx.

Michael Michalko (2001) Cracking Creativity the seccreats of creative genius Business, Education, \& Personal, diterjemahkan oleh Dwi Prabantini(2010) Yogyakarta, Andi

Nuning. W., M. M. (2015). Metode Penciptaan Bidang Seni Rupa: Praktek Berbasis Penelitian (practice based risearch), Karya Seni Sebagai Produksi Pengetahuan dan Wacana. CORAK, 4(1). https://doi.org/10.24821/corak.v4i1.2358

Sigit Purnama (2009), Teknik Finishing Mebel, Semarang, Dahara Prize Hughes, Richard; Rowe, Michael (1995). The Colouring, Bronzing, dan Patination of Metals . London: Thames \& Hudson Ltd. ISBN 978-0-500-01501-8.

http://www.infometrik.com/2009/08/pelapisan-logam-bagian-1/ https://nurlailiarum.blogspot.com/2010/09/penyepuhan-logam.html 
AKSARA: Jurnal Ilmu Pendidikan Nonformal

P-ISSN 2407-8018 E-ISSN 2721-7310 DOI prefix $\underline{10.37905}$

Volume 08, (1), January 2022

http://ejurnal.pps.ung.ac.id/index.php/Aksara 